\title{
The oral health of individuals with dental phobia: a multivariate analysis of the Adult Dental Health Survey, 2009
}

\author{
E. Heidari, ${ }^{* 1}$ M. Andiappan, ${ }^{2}$ A. Banerjee ${ }^{3}$ and J. T. Newton ${ }^{4}$
}

\section{In brief}

Provides an understanding about the 2009 Adult Dental Health Survey results in relation to people who have dental phobia.
Provides an overview of dental phobia sufferers' oral health status and how to plan for their dental care.
Suggests that people with dental phobia might present with poorer quality of life as a result of their oral health status.

Background Adults with dental phobia have been reported to have poorer oral health and oral health-related quality of life. The aim of this study is to explore the social and demographic correlates of oral health and oral health-related quality of life (OH-QoL) of people with dental phobia compared to the non-phobic population in the United Kingdom using the data from Adult Dental Health Survey (ADHS, 2009). Method Secondary analysis of data from the ADHS, 2009. A series of logistic regression analyses was performed with outcome measures of: presence of decayed teeth; presence of missing teeth; pulp exposure ulceration fistula abscess (PUFA) score; periodontal health indices (plaque, bleeding and loss of attachments); and quality of life (oral health impact profile [OHIP14] and oral impacts on daily performance [OIDP]). Predictors included in the models were: the presence of dental phobia; age; gender; occupational status; oral health-related behaviour; dietary intake of sugars; and perception of their last visit. Results People with dental phobia are more likely to have one or more decayed (caries) teeth/missing teeth. Furthermore, their selfreported oral health-related quality of life $(\mathrm{OH}-\mathrm{QoL})$ is poorer. There were no differences in PUFA scores or periodontal disease. Conclusion The impact of dental phobia on oral health appears to operate largely through the increased likelihood of the presence of caries, since there is an increased likelihood of the presence of teeth with active caries and missing teeth when other predictors of disease experience are controlled in the analysis.

\section{Introduction}

Dental phobia is classified as a specific phobia within the Diagnostic and Statistical Manual of Mental Disorders (DSM5, 2013) and is characterised as a disproportionate fear in the presence or anticipation of the feared object eliciting a marked anxiety response, of which the individual is aware, and which has a

${ }^{1}$ Senior Specialist Clinical Teacher; ${ }^{2}$ Biostatistician; ${ }^{3 P r o f e s}$ sor of Cariology and Operative Dentistry/ Hon Consultant \& Clinical Lead, Restorative Dentistry; ${ }^{4}$ Professor of Psychology as applied to Dentistry/Hon Consultant, King's College London Dental Institute, Guy's Dental Hospital, Great Maze

Pond, London, SE1 9RT, United Kingdom

${ }^{*}$ Correspondence to: Dr Ellie Heidari

Email: ellie.heidarikcl.ac.uk

Refereed Paper. Accepted 3 January 2017

DOI: 10.1038/sj.bdj.2017.361

๑British Dental Journal 2017; 222: 595-604 marked impact on the individual's normal life and/or wellbeing. Aside from the social and psychological impact of a dental phobia, ${ }^{1}$ there is also an impact on oral health-related quality of life (OH-QoL) and oral health. ${ }^{2}$ Within the United Kingdom, an analysis of data from the Adult Health Survey (ADHS) found that individuals with phobic levels of dental anxiety reported lower levels of self-rated oral health, lower levels of general health and were more likely to perceive that they would require dental treatment should they visit a dentist. Furthermore, the authors reported that individuals with dental phobia expressed higher levels of impact of their oral health on quality of life (OHIP and OIDP data). However, in terms of those individuals who were examined clinically, the only significant differences in clinical status were: increased levels of caries, increased PUFA score, increased plaque and bleeding. ${ }^{2}$ This contrasted with previous research suggesting that individuals with dental phobia have higher numbers of missing teeth and decreased numbers of filled teeth. ${ }^{3-7}$ However, Heidari et al. ${ }^{2}$ failed to control for socio-demographic differences between the phobic and non-phobic participants, which are likely to have influenced the findings given that the individuals with dental phobia were more likely to be female, younger, have lower levels of education and social status and were more likely to have a long-standing illness. These socio-demographic variables are known to be strongly predictive of oral disease. ${ }^{8}$

The aim of this study is to explore the social and demographic correlates of oral health and oral health-related quality of life (OH-QoL) of people with dental phobia compared to the 
non-phobic population in the United Kingdom using the data from the Adult Dental Health Survey. ${ }^{9}$ The outcome measures chosen were: presence of decayed teeth; presence of missing teeth; pulp exposure ulceration fistula abscess (PUFA) score; periodontal health indices (plaque, bleeding and loss of attachments); and quality of life (oral health impact profile [OHIP14] and oral impacts on daily performance [OIDP]). The socio-demographic characteristics, behaviours and attitudes included in the predictive models were: the presence of dental phobia; age; gender; occupational status; oral health-related behaviour; dietary intake of sugars; and perception of their last visit.

\section{Materials and methods}

\section{Data source}

The complete data set for the Adult Dental Health Survey (2009) was accessed with permission from the UK Data Service (http:// ukdataservice.ac.uk/). ${ }^{9}$ Full details of the methodology of the survey can been found in O'Sullivan et al., ${ }^{10}$ while descriptive statistics and a univariate comparison of the phobic and non-phobic participants can be found in Heidari et al. ${ }^{2}$

\section{Outcomes}

The following outcome measures were considered for the analysis:

- Caries experience (presence of any decay vs absence of decay). According to ADHS, ${ }^{10}$ decay was classified as: 'teeth with visual caries or cavitated caries or teeth that were so broken down, possibly with pulpal involvement, that they were unrestorable. It includes teeth that had restorations with recurrent caries but does not include teeth that had restorations which were lost, broken or damaged but where there was no recurrent caries'

- Number of missing teeth (dichotomised as any missing teeth vs no missing teeth)

- Periodontal health and the Basic Periodontal Examination (BPE) only assessed in participants aged 35 and over

o Plaque score (presence versus or absence of plaque) $(\mathrm{N}=2,939)$

o Bleeding on probing (presence or absence of any bleeding on probing) $(\mathrm{N}=2,931)$

o Loss of attachment (measured for participants aged $\geq 55$ years, $\mathrm{N}=1,366$, dichotomised as 0 to $3.4 \mathrm{~mm}$ vs $\geq 3.5 \mathrm{~mm}$ )
- Pulp involvement ulceration fistulae abscess (PUFA) score (scored as 0 or 1 for presence of any element)

- Oral health-related quality of life

- Oral health impact profile: OHIP14 total score

- Oral impacts on daily performance: OIDP total score.

\section{Predictors}

The following potential predictor variables were used in the model to find out the significant predictors of the above outcome measures:

- Dental anxiety (MDAS, dichotomised as phobic: Total MDAS >= 19 or non-phobic: total MDAS <19)

- Socio-demographic variables:

- Gender (male/female)

o Age (classified into bands 16-24; 25-34; 35-44; 45-54; 55-64; 65-74; 75 and over)

o Social class (classified in groups: managerial and professional occupations; intermediate occupations; small employers and own account worker; lower supervisory and technical occupations; semi-routine and routine occupations; never worked and unemployed).

- Oral health-related behaviours:

o Intake of dietary sugars: Frequency of eating cake (six or more times per week, three to five times/week, one to two times/week, rarely); Frequency of confectionery and sugary drinks (six or more times per week, three to five times/ week, one to two times/week, rarely).

o Use of floss (mentioned vs not mentioned)

o Use of interdental brush (mentioned vs not mentioned)

o Use of mouthwash (mentioned vs not mentioned)

o Use of interspace brush (mentioned vs not mentioned)

o Use of electric toothbrush (mentioned vs not mentioned)

o Use of sugar-free gum (mentioned vs not mentioned)

- Perceptions of most recent dental visit:

o Dentist listened carefully (vs did not listen)

o There was sufficient time to discuss the problem (vs insufficient time).

\section{Analysis}

For the binary outcome measures, logistic regression models with the above predictor variables were used to find out the significant predictors of the outcome. As the total OHIP, OIDP and PUFA scores did not follow normal distribution, general linear model (GLM) with Gamma family and log link was fitted separately for each of these outcome measures. For the clinical outcome measures (except PUFA score) the predictors listed above were included in the model. For the oral health-related quality of life outcomes and the PUFA score, in addition to the predictors outlined above, the clinical indicators of presence/absence of decay, missing teeth and periodontal health were also included in the models. The statistical significance was assessed at 5\% level and all the analyses were carried out using SPSS version 22.0 or STATA 12.

\section{Results}

The data comprised 10,900 participants of whom a total of $1,367(12.4 \%)$ subjects were identified as phobic (MDAS score $\geq 19$ ). Of these, 344 (25\%) were male and 1,023 (75\%) female. Other details of the demographic characteristics of phobic and non-phobic participants can be found in Heidari et al. ${ }^{2}$

\section{Oral health status}

Phobic people were more likely to have caries in comparison to non-phobic respondents (Table 1). Other factors that contributed to significant caries levels were if participants were male, brushed their teeth infrequently (never or occasionally) and did not use a range of oral hygiene products (mouthwash, floss, interspace cleaning, sugar-free gum and use of electric toothbrush) and felt that the dentist did not listen carefully to them at their last visit.

Phobic individuals were more likely to have one or more missing teeth, after correction for other socio-demographic factors. Loss of teeth was also associated with being female, and in older age groups and lower social classes (Table 2).

The presence of dental phobia was not related to periodontal loss of attachment (LoA). The significant predictors of loss of attachment were gender, age and the use of floss - the latter being protective against LoA (see Table 3). Similarly, bleeding on probing was not related to the presence of dental phobia, but was less prevalent among those who reported using dental floss (Table 4).

As shown in Table 5 the presence of plaque was highest among those who were: male, aged 55 to 64 or 75 and over, from semi-routine and routine occupations and those who did not 
mention using floss. The presence of dental phobia was not associated with plaque.

There was no significant relationship between the presence of dental phobia and PUFA score (Table 6). However, people who had decayed teeth and plaque had higher PUFA scores as well as those who used mouthwash and felt that the dentist had not listened to them at their most recent visit.

\section{Oral health-related quality of life}

There was a significant relationship between dental phobia and OHIP score with individuals with dental phobia reporting higher levels of negative impact on their oral health-related quality of life for both OHIP (Table 7) and OIDP (Table 8). The presence of caries was also significant in both models.

\section{Discussion}

This study reports the findings of multivariate analyses comparing individuals defined as phobic of dental treatment or non-phobic on the basis of a questionnaire assessment of dental anxiety - the Modified Dental Anxiety
Scale (MDAS). The MDAS has good reliability and validity, and the cut-offs for 'phobic' respondents at scores of 19 and above is well defined. ${ }^{11}$ People with dental phobia are more likely to have one or more decayed teeth and missing teeth. Furthermore, their self-reported oral health-related quality of life (OH-QoL) is poorer. There was no relationship between phobia and PUFA score or periodontal disease indices. The persistence of an effect of perceptions of the dentists' listening when dental phobia is controlled is interesting and worthy of future research.

\section{Table 1 Results of logistic regression of caries status (1 or more teeth with decay) for various predictor variables $(\mathrm{N}=3,766)$}

\begin{tabular}{|c|c|c|c|c|}
\hline Predictors & Comparison group & $P$ value & Odds ratio & $\begin{array}{l}95 \% \text { Confidence } \\
\text { interval }\end{array}$ \\
\hline Is phobic & The participant is not phobic & 0.003 & 1.42 & 1.12 to 1.80 \\
\hline Sex & Male & 0.004 & 0.78 & 0.66 to 0.93 \\
\hline 25 to 34 & \multirow{6}{*}{ The youngest age group: 16 to 24} & 0.09 & 1.33 & 0.96 to 1.86 \\
\hline 35 to 44 & & 0.79 & 0.96 & 0.70 to 1.32 \\
\hline 45 to 54 & & 0.04 & 0.7 & 0.53 to 0.99 \\
\hline 55 to 64 & & 0.08 & 0.74 & 0.52 to 1.04 \\
\hline 65 to 74 & & 0.02 & 0.65 & 0.44 to 0.95 \\
\hline 75 \& over & & 0.2 & 1.31 & 0.86 to 1.98 \\
\hline Intermediate occupations & \multirow{5}{*}{ Managerial and professional occupations } & 0.97 & 1 & 0.77 to 1.30 \\
\hline Small employers \& own account workers & & 0.77 & 0.95 & 0.70 to 1.30 \\
\hline Lower supervisory \& technical occupations & & 0.57 & 1.09 & 0.82 to 1.45 \\
\hline Semi routine and routine occupations & & 0.06 & 1.21 & 0.99 to 1.48 \\
\hline Never worked & & 0.76 & 0.94 & 0.64 to 1.38 \\
\hline Floss has been mentioned & Has not been mentioned & 0.0001 & 0.64 & 0.54 to 0.75 \\
\hline Interdental brush has been mentioned & Has not been mentioned & 0.34 & 0.88 & 0.70 to 1.13 \\
\hline Mouthwash has been mentioned & Has not been mentioned & 0.034 & 1.2 & 1.01 to 1.42 \\
\hline Interspace brush has been mentioned & Has not been mentioned & 0.02 & 0.71 & 0.54 to 0.94 \\
\hline Electric tooth brush has been mentioned & Has not been mentioned & 0.03 & 0.83 & 0.70 to 0.98 \\
\hline Sugar-free gum has been mentioned & Has not been mentioned & 0.04 & 1.47 & 1.03 to 2.10 \\
\hline 3-5 times/w & \multirow{3}{*}{ Participants have fizzy drinks 6 or more times a week } & 0.43 & 0.9 & 0.69 to 1.17 \\
\hline $1-2$ times/w & & 0.37 & 1.12 & 0.88 to 1.43 \\
\hline Rarely & & 0.53 & 0.94 & 0.77 to 1.14 \\
\hline Twice a day & \multirow{4}{*}{ Participants clean teeth their teeth more than twice a day } & 0.32 & 0.89 & 0.71 to 1.12 \\
\hline Once a day & & 0.27 & 1.16 & 0.89 to 1.52 \\
\hline Never & & 0.04 & 10.04 & 1.10 to 93.29 \\
\hline Occasionally & & 0.008 & 2.18 & 1.22 to 3.89 \\
\hline Dentist did not listen carefully & Dentist listened carefully & 0.02 & 1.43 & 1.07 to 1.91 \\
\hline It was not enough time to discuss & It was enough time to discuss & 0.95 & 0.99 & 0.79 to 1.25 \\
\hline
\end{tabular}




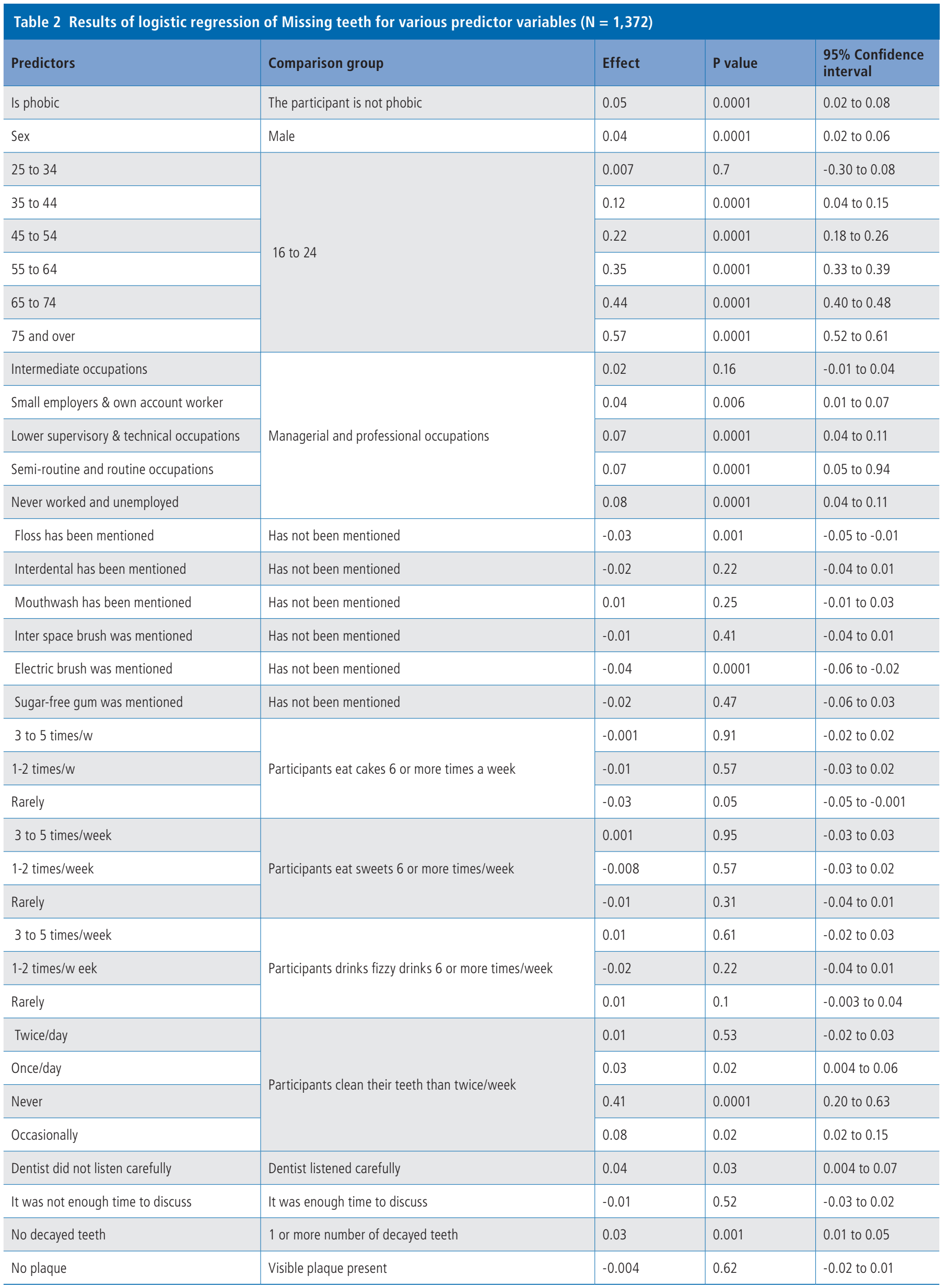


Many people with dental phobia avoid seeing a dentist ${ }^{12,13}$ on a regular basis to address oral diseases (such as caries and periodontal disease) that are preventable and chronic in nature. Once a visit has been made, the phobic patient might prefer a short-term solution of the symptomatic tooth or prefer an extraction..$^{14,15}$ Alternatively, differences in the likelihood of having missing teeth may relate to treatment decisions made when the individual with dental phobia finally seeks treatment - with a history of repeated non-attendance practitioners may favour extraction of a tooth rather than booking a number of appointments to complete a complex restoration. Interestingly, there was no relationship between phobia and PUFA. Given that dental phobia is associated with avoidance of dental treatment it could be assumed that they might present with long-standing disease and its consequences presented as PUFA, however, fortunately, this does not appear to be the case.

Previous research has found that greater dental anxiety is associated with more decayed ${ }^{16}$ and missing teeth..$^{14,15,17}$ The findings of this study contrast with previous research which has reported higher levels of periodontal disease in individuals with dental phobia. ${ }^{18}$ The reasons for this are unclear but may relate to the clinical observation that individuals with dental phobia report engaging in oral hygiene in an attempt to mitigate the need for dental visits. Furthermore, phobic participants in a qualitative study reported making a conscious effort to take care of their teeth.

Oral diseases are not normally life threatening but can affect people's 'ability to eat, drink, speak and socialize. ${ }^{19}$ This will have an impact on QoL, ${ }^{16,19,20}$ affecting their physiological, psychological, social and emotional wellbeing. ${ }^{14,21,22}$ People with dental phobia showed higher scores for OHIP and OIDP even when levels of dental disease were accounted for in the control. One possible explanation is that individuals with dental phobia express negative feelings such as sadness, tiredness, discouragement and general anxiety, ${ }^{16}$ less vitality and more exhaustion. Embarrassment (a combination of guilt and bad conscience) of their poor teeth will prevent them from smiling and showing their teeth because phobic people rate their oral and general health as poor and frequently perceive that they would require dental treatment upon a dental visit. ${ }^{16}$ This highly perceived need leads to feelings of negative social evaluation, and powerlessness ${ }^{23}$ as well as having a negative effect on their attitude towards dental attendance. ${ }^{24}$ This potentially has an impact on work situations, personal life and relationships with family members ${ }^{1,6,25}$ which are affected by their negative thoughts and feelings, lack of self-esteem/confidence and sleep. ${ }^{23}$

The data presented in this study is extracted from ADHS. The methodology for ADHS has been refined and evolved for each decade using validated questionnaires and calibrated examiners. Another strength of ADHS is the large random sample who volunteer to have a clinical examination rather than the care seeking population attending in a specialised clinic that has traditionally been the case within this field. A limitation of ADHS, is the use of questionnaires which may potentially be subject to problems of recall and retrospective re-interpretation. ${ }^{26}$ Furthermore the cross-sectional nature of the study does not allow the determination of causal pathways. The use of a questionnaire to define the presence of phobia may not be entirely accurate, though the MDAS has been extensively validated against clinical judgement.

\section{Conclusion}

Individuals with dental phobia experience an increased likelihood of the presence of teeth with active caries and missing teeth. The findings have implications for the development of preventive services for individuals with dental phobia.

\begin{tabular}{|c|c|c|c|c|}
\hline Predictors & Comparison group & P value & Odds ratio & $\begin{array}{l}95 \% \text { Confidence } \\
\text { interval }\end{array}$ \\
\hline Is phobic & The participant is not phobic & 0.57 & 0.88 & 0.57 to 1.36 \\
\hline Sex & Male & 0.001 & 0.66 & 0.51 to 0.85 \\
\hline 65 to 74 & \multirow{2}{*}{ Age group: 55 to 64} & 0.13 & 1.22 & 0.95 to 1.57 \\
\hline 75 \& over & & 0.001 & 1.85 & 1.28 to 2.67 \\
\hline Intermediate occupations & \multirow{5}{*}{ Managerial and professional occupations } & 0.18 & 0.78 & 0.55 to 1.12 \\
\hline Small employers \& own account workers & & 0.61 & 1.1 & 0.74 to 1.66 \\
\hline Lower supervisory \& technical occupations & & 0.04 & 1.61 & 1.02 to 2.57 \\
\hline Semi routine and routine occupations & & 0.47 & 1.12 & 0.82 to 1.52 \\
\hline Never worked & & 0.73 & 1.11 & 0.65 to 1.86 \\
\hline Floss has been mentioned & Has not been mentioned & 0.001 & 0.65 & 0.51 to 0.83 \\
\hline Electric brush has been mentioned & Has not been mentioned & 0.14 & 0.84 & 0.67 to 1.06 \\
\hline Sugar-free gum has been mentioned & Has not been mentioned & 0.31 & 0.62 & 0.25 to 1.55 \\
\hline Twice a day & \multirow{4}{*}{ Participants clean teeth their teeth more than twice a day } & 0.72 & 0.94 & 0.69 to 1.30 \\
\hline Once a day & & 0.64 & 0.92 & 0.62 to 1.35 \\
\hline Never & & 0.98 & 0.97 & 0.10 to 9.71 \\
\hline Occasionally & & 0.62 & 0.76 & 0.26 to 2.21 \\
\hline
\end{tabular}




\begin{tabular}{|c|c|c|c|c|}
\hline Predictors & Comparison group & $P$ value & Odds ratio & $\begin{array}{l}95 \% \text { Confidence } \\
\text { interval }\end{array}$ \\
\hline Is phobic & The participant is not phobic & 0.59 & 1.07 & 0.83 to 1.40 \\
\hline Sex & Male & 0.64 & 0.96 & 0.82 to 1.13 \\
\hline 45 to 54 & \multirow{4}{*}{ Age group is 35 to 44} & 0.006 & 1.33 & 1.10 to 1.64 \\
\hline 55 to 64 & & 0.17 & 1.16 & 0.94 to 1.43 \\
\hline 65 to 74 & & 0.27 & 0.87 & 0.70 to 1.11 \\
\hline 75 \& over & & 0.68 & 0.93 & 0.68 to 1.30 \\
\hline Intermediate occupations & \multirow{5}{*}{ Managerial and professional occupations } & 0.43 & 1.1 & 0.87 to 1.40 \\
\hline Small employers \& own account workers & & 0.58 & 0.93 & 0.71 to 1.21 \\
\hline Lower supervisory \& technical occupations & & 0.8 & 0.96 & 0.72 to 1.30 \\
\hline Semi routine and routine occupations & & 0.03 & 1.25 & 1.02 to 1.53 \\
\hline Never worked & & 0.55 & 1.13 & 0.75 to 1.71 \\
\hline Floss has been mentioned & Has not been mentioned & 0.0001 & 0.68 & 0.58 to 0.80 \\
\hline Interdental brush has been mentioned & Has not been mentioned & 0.02 & 0.78 & 0.64 to 0.97 \\
\hline Mouthwash has been mentioned & Has not been mentioned & 0.02 & 1.2 & 1.02 to 1.40 \\
\hline Electric brush has been mentioned & Has not been Mentioned & 0.98 & 0.99 & 0.81 to 1.22 \\
\hline 3 to 5 times/w & \multirow{3}{*}{ Participants eat cakes 6 or more times a week } & 0.99 & 0.99 & 0.81 to 1.22 \\
\hline $1-2$ times/w & & 0.64 & 1.05 & 0.85 to 1.30 \\
\hline Rarely & & 0.85 & 1.02 & 0.80 to 1.30 \\
\hline 3 to 5 times/week & \multirow{3}{*}{ Participants eat sweets 6 or more times/week } & 0.55 & 0.71 & 0.71 to 1.20 \\
\hline 1-2 times/week & & 0.33 & 0.88 & 0.69 to 1.13 \\
\hline Rarely & & 0.62 & 1.06 & 0.83 to 1.37 \\
\hline Twice/day & \multirow{4}{*}{ Participants clean their teeth more than twice/week } & 0.42 & 0.92 & 0.74 to 1.13 \\
\hline Once/day & & 0.94 & 0.99 & 0.76 to 1.29 \\
\hline Never & & 0.24 & 0.25 & 0.03 to 2.51 \\
\hline Occasionally & & 0.003 & 3.95 & 1.61 to 9.73 \\
\hline Dentist did not listen carefully & Dentist listened carefully & 0.44 & 1.13 & 0.83 to 1.54 \\
\hline It was not enough time to discuss & It was enough time to discuss & 0.82 & 1.03 & 0.82 to 1.30 \\
\hline
\end{tabular}

\begin{tabular}{|c|c|c|c|c|}
\hline Predictors & Comparison group & $P$ value & Odds ratio & $\begin{array}{l}95 \% \text { Confidence } \\
\text { interval }\end{array}$ \\
\hline Is phobic & The participant is not phobic & 0.19 & 1.2 & 0.91 to 1.55 \\
\hline Sex & Male & 0.0001 & 0.65 & 0.55 to 0.77 \\
\hline 45 to 54 & \multirow{4}{*}{ The youngest group is 35 to 44} & 0.33 & 1.11 & 0.90 to 1.36 \\
\hline 55 to 64 & & 0.003 & 1.4 & 1.12 to 1.73 \\
\hline 65 to 74 & & 0.44 & 1.1 & 0.86 to 1.42 \\
\hline 75 \& over & & 0.004 & 1.67 & 1.18 to 2.37 \\
\hline
\end{tabular}




\begin{tabular}{|c|c|c|c|c|}
\hline Predictors & Comparison group & $P$ value & Odds ratio & $\begin{array}{l}95 \% \text { Confidence } \\
\text { interval }\end{array}$ \\
\hline Intermediate occupations & \multirow{5}{*}{ Managerial and professional occupations } & 0.83 & 1.03 & 0.81 to 1.30 \\
\hline Small employers \& own account workers & & 0.25 & 1.17 & 0.89 to 1.55 \\
\hline Lower supervisory \& technical occupations & & 0.05 & 1.36 & 0.99 to 1.86 \\
\hline Semi routine and routine occupations & & 0.004 & 1.36 & 1.11 to 1.68 \\
\hline Never worked & & 0.073 & 1.5 & 0.96 to 2.32 \\
\hline Floss has been mentioned & Has not been mentioned & 0.0001 & 0.73 & 0.63 to 0.86 \\
\hline Mouthwash has been mentioned & Has not been mentioned & 0.01 & 1.22 & 1.04 to 1.44 \\
\hline Electric brush has been mentioned & Has not been mentioned & 0.01 & 0.82 & 0.70 to 0.96 \\
\hline 3 to 5 times/w & \multirow{3}{*}{ Participants eat cakes 6 or more times a week } & 0.09 & 1.2 & 0.97 to 1.49 \\
\hline $1-2$ times/w & & 0.12 & 1.19 & 0.96 to 1.47 \\
\hline Rarely & & 0.24 & 1.16 & 0.91 to 1.50 \\
\hline 3 to 5 times/week & \multirow{3}{*}{ Participants eat sweets 6 or more times/week } & 0.98 & 0.99 & 0.76 to 1.31 \\
\hline 1-2 times/week & & 0.95 & 0.99 & 0.77 to 1.28 \\
\hline Rarely & & 1.21 & 1.23 & 0.95 to 1.59 \\
\hline Twice/day & \multirow{4}{*}{ Participants clean their teeth more than twice/week } & 0.4 & 0.91 & 0.73 to 1.13 \\
\hline Once/day & & 0.94 & 1.01 & 0.77 to 1.32 \\
\hline Never & & 0.99 & $"-"$ & $"-"$ \\
\hline Occasionally & & 0.1 & 2.03 & 0.86 to 4.76 \\
\hline Dentist did not listen carefully & Dentist listened carefully & 0.7 & 1.1 & 0.77 to 1.47 \\
\hline It was not enough time to discuss & It was enough time to discuss & 0.88 & 0.98 & 0.77 to 1.24 \\
\hline
\end{tabular}

\section{Table 6 Results of general Linear Model (GLM) of PUFA scores with various predictor variables $(\mathrm{N}=3,812$ ) (Cont. on page 602$)$}

\begin{tabular}{|c|c|c|c|c|}
\hline Predictors & Comparison group & $P$ value & Odds ratio & $\begin{array}{l}95 \% \text { Confidence } \\
\text { interval }\end{array}$ \\
\hline Is phobic & The participant is not phobic & 0.35 & 0.09 & $-0.05-0.75$ \\
\hline Sex & Male & -0.70 & 0.67 & -0.40 to 0.26 \\
\hline 25 to 34 & \multirow{6}{*}{16 to 24} & 0.41 & 0.24 & -0.27 to -0.60 \\
\hline 34 to 44 & & 0.14 & 0.7 & 1.10 to 0.88 \\
\hline 45 to 54 & & 0.25 & 0.49 & -0.47 to 0.98 \\
\hline 55 to 64 & & 0.98 & 0.005 & 0.30 to 1.67 \\
\hline 65 to 74 & & 0.74 & 0.06 & -0.04 to 1.52 \\
\hline 75 and over & & 1.13 & 0.002 & 0.40 to 1.86 \\
\hline Intermediate occupations & \multirow{5}{*}{ Managerial and professional occupations } & 0.3 & 0.25 & -0.20 to 0.80 \\
\hline Small employers \& own account workers & & 0.47 & 0.1 & -0.08 to 1.01 \\
\hline Lower supervisory \& technical occupations & & -0.02 & 0.95 & -0.55 to 0.51 \\
\hline Semi routine and routine occupations & & 0.17 & 0.4 & -0.22 to 0.56 \\
\hline Never worked and unemployed & & 0.8 & 0.03 & 0.09 to 1.51 \\
\hline Floss has been mentioned & Has not been mentioned & -0.25 & 0.15 & -0.60 to 0.09 \\
\hline Interdental has been mentioned & Has not been mentioned & 0.07 & 0.75 & -0.35 to 0.48 \\
\hline
\end{tabular}




\begin{tabular}{|c|c|c|c|c|}
\hline Predictors & Comparison group & $P$ value & Odds ratio & $\begin{array}{l}95 \% \text { Confidence } \\
\text { interval }\end{array}$ \\
\hline Mouthwash has been mentioned & Has not been mentioned & 0.56 & 0.0001 & 0.25 to 0.88 \\
\hline Inter space brush was mentioned & Has not been mentioned & -0.35 & 0.22 & -0.91 to 0.21 \\
\hline Electric brush was mentioned & Has not been mentioned & 0.01 & 0.94 & -0.29 to 0.31 \\
\hline Sugar-free gum was mentioned & Has not been mentioned & -0.45 & 0.26 & -1.23 to 0.33 \\
\hline 3 to 5 times/w & \multirow{3}{*}{ Participants eat cakes 6 or more times a week } & 0.14 & 0.51 & -0.29 to 0.58 \\
\hline $1-2$ times/w & & 0.1 & 0.64 & -0.32 to 0.53 \\
\hline Rarely & & 0.1 & 0.71 & -0.44 to 0.65 \\
\hline 3 to 5 times/week & \multirow{3}{*}{ Participants eat sweets 6 or more times/week } & 0.26 & 0.32 & -0.26 to 0.78 \\
\hline 1-2 times/week & & 0.02 & 0.93 & -0.47 to 0.52 \\
\hline Rarely & & 0.23 & 0.36 & -0.27 to 0.74 \\
\hline 3 to 5 times/week & \multirow{3}{*}{ Participants drinks fizzy drinks 6 or more times/week } & 0.02 & 0.92 & -0.47 to 0.52 \\
\hline 1-2 times/w eek & & -0.24 & 0.37 & -0.76 to 0.28 \\
\hline Rarely & & -0.11 & 0.55 & -0.49 to 0.26 \\
\hline Twice/day & \multirow{4}{*}{ Participants clean their teeth than twice/week } & -0.24 & 0.31 & -0.71 to 0.23 \\
\hline Once/day & & 0.03 & 0.92 & -0.47 to 0.53 \\
\hline Never & & 0.55 & 0.5 & -1.10 to 2.20 \\
\hline Occasionally & & -0.20 & 0.66 & -1.10 to 0.70 \\
\hline Dentist did not listen carefully & Dentist listened carefully & 0.96 & 0.0001 & 0.45 to 1.47 \\
\hline It was not enough time to discuss & It was enough time to discuss & -0.26 & 0.3 & -0.74 to 0.23 \\
\hline No decayed teeth & 1 or more number of decayed teeth & 1.52 & 0.0001 & 1.22 to 1.82 \\
\hline No plaque & Visible plaque present & 0.57 & 0.003 & 0.18 to 0.94 \\
\hline
\end{tabular}

\section{Table 7 Results of general Linear Model (GLM) of OHIP scores with various predictor variables $(n=3,807)$ (Cont. on page 603)}

\begin{tabular}{|c|c|c|c|c|}
\hline Predictors & Comparison group & $P$ value & Odds ratio & $\begin{array}{l}95 \% \text { Confidence } \\
\text { interval }\end{array}$ \\
\hline Is phobic & The participant is not phobic & 0.45 & 0.0001 & 0.30 to 0.61 \\
\hline Sex & Male & 0.13 & 0.03 & 0.01 to 0.25 \\
\hline 25 to 34 & \multirow{6}{*}{ The youngest group is 16 to 24} & 0.25 & 0.05 & 0.000 to 0.51 \\
\hline 34 to 44 & & 0.31 & 0.01 & 0.07 to 0.56 \\
\hline 45 to 54 & & 0.4 & 0.001 & 0.15 to 0.65 \\
\hline 55 to 64 & & 0.4 & 0.002 & 0.14 to 0.65 \\
\hline 65 to 74 & & 0.25 & 0.08 & -0.03 to 0.53 \\
\hline 75 \& over & & 0.01 & 0.96 & -0.32 to 0.34 \\
\hline Intermediate occupations & \multirow{5}{*}{ Managerial and professional occupations } & 0.22 & 0.02 & 0.04 to 0.41 \\
\hline Small employers \& own account workers & & 0.17 & 0.1 & -0.03 to 0.37 \\
\hline Lower supervisory \& technical occupations & & 0.31 & 0.003 & 0.11 to 0.52 \\
\hline Semi routine and routine occupations & & 0.22 & 0.003 & 0.76 to 0.36 \\
\hline Never worked and unemployed & & -0.01 & 0.92 & -0.31 to 0.28 \\
\hline
\end{tabular}




\begin{tabular}{|c|c|c|c|c|}
\hline Predictors & Comparison group & $P$ value & Odds ratio & $\begin{array}{l}95 \% \text { Confidence } \\
\text { interval }\end{array}$ \\
\hline Floss has been mentioned & Has not been mentioned & -0.90 & 0.13 & -0.21 to 0.03 \\
\hline Interdental has been mentioned & Has not been mentioned & 0.22 & 0.003 & 0.08 to 0.38 \\
\hline Mouthwash has been mentioned & Has not been mentioned & 0.2 & 0.001 & 0.08 to 0.31 \\
\hline Inter space brush has been mentioned & Has not been mentioned & 0.2 & 0.02 & 0.03 to 0.38 \\
\hline Electric brush has been mentioned & Has not been mentioned & -0.26 & 0.0001 & -0.37 to -0.14 \\
\hline Sugar-free gum has been mentioned & Has not been mentioned & 0.18 & 0.1 & -0.03 to 0.40 \\
\hline 3 to 5 times/w & \multirow{3}{*}{ Participants eat cakes 6 or more times a week } & 0.01 & 0.89 & -0.14 to 0.16 \\
\hline $1-2$ times/w & & 0.06 & 0.47 & -0.09 to 0.21 \\
\hline Rarely & & -0.03 & 0.78 & -0.22 to 0.16 \\
\hline 3 to 5 times/week & \multirow{3}{*}{ Participants eat sweets 6 or more times/week } & -0.02 & 0.85 & -0.20 to 0.17 \\
\hline 1-2 times/week & & -0.25 & 0.008 & -0.43 to -0.06 \\
\hline Rarely & & -0.08 & 0.41 & -0.27 to 0.11 \\
\hline 3 to 5 times/week & \multirow{3}{*}{ Participants drinks fizzy drinks 6 or more times/week } & 0.09 & 0.35 & -0.09 to 0.27 \\
\hline 1-2 times/w eek & & 0.02 & 0.82 & -0.16 to 0.20 \\
\hline Rarely & & 0.009 & 0.9 & -0.13 to 0.14 \\
\hline Twice/day & \multirow{4}{*}{ Participants clean their teeth 6 or more than twice/week } & -0.12 & 0.14 & -0.28 to 0.04 \\
\hline Once/day & & 0.01 & 0.88 & -0.17 to 0.20 \\
\hline Never & & 0.5 & 0.28 & -0.40 to 1.40 \\
\hline Occasionally & & 0.25 & 0.15 & -0.09 to 0.58 \\
\hline Dentist did not listen carefully & Dentist listened carefully & 0.49 & 0.0001 & 0.29 to 0.70 \\
\hline It was not enough time to discuss & It was enough time to discuss & 0.05 & 0.6 & -0.12 t 0.22 \\
\hline No decayed teeth & 1 or more number of decayed teeth & 0.3 & 0.0001 & 0.18 to 0.43 \\
\hline No plaque & Visible plaque present & 0.005 & 0.93 & -0.11 to 0.12 \\
\hline
\end{tabular}

Table 8 Results of general Linear Model (GLM) of OIDP scores with various predictor variables $(n=3,812)$ (Cont. on page 604)

\begin{tabular}{|c|c|c|c|c|}
\hline Predictors & Comparison group & $P$ value & Odds ratio & $\begin{array}{l}95 \% \text { Confidence } \\
\text { interval }\end{array}$ \\
\hline Is phobic & The participant is not phobic & 0.72 & 0.0001 & 0.52 to 0.92 \\
\hline Sex & Male & 0.08 & 0.32 & -0.08 to 0.24 \\
\hline 25 to 34 & \multirow{6}{*}{16 to 24} & 0.03 & 0.87 & -0.31 to 0.37 \\
\hline 35 to 44 & & 0.08 & 0.65 & -0.25 to 0.41 \\
\hline 45 to 54 & & 0.25 & 0.14 & -0.08 to 0.58 \\
\hline 55 to 64 & & 0.19 & 0.28 & -0.16 to 0.54 \\
\hline 65 to 74 & & -0.10 & 0.59 & -0.47 to 0.26 \\
\hline 75 and over & & -0.52 & 0.02 & -0.97 to -0.06 \\
\hline Intermediate occupations & \multirow{5}{*}{ Managerial and professional occupations } & 0.04 & 0.71 & -0.18 to 0.26 \\
\hline Small employers \& own account workers & & 0.14 & 0.32 & -0.14 to 0.43 \\
\hline Lower supervisory \& technical occupations & & 0.26 & 0.08 & -0.03 to 0.54 \\
\hline Semi routine and routine occupations & & 0.16 & 0.1 & -0.03 to 0.35 \\
\hline Never worked and unemployed & & -0.04 & 0.87 & -0.47 to 0.39 \\
\hline
\end{tabular}




\begin{tabular}{|c|c|c|c|c|}
\hline Predictors & Comparison group & $P$ value & Odds ratio & $\begin{array}{l}95 \% \text { Confidence } \\
\text { interval }\end{array}$ \\
\hline Floss has been mentioned & Has not been mentioned & -0.17 & 0.03 & -0.33 to -0.01 \\
\hline Interdental has been mentioned & Has not been mentioned & 0.3 & 0.005 & 0.09 to 0.50 \\
\hline Mouthwash has been mentioned & Has not been mentioned & 0.3 & 0.0001 & 0.12 to 0.42 \\
\hline Inter space brush was mentioned & Has not been mentioned & 0.07 & 0.54 & -0.15 to 0.30 \\
\hline Electric brush was mentioned & Has not been mentioned & -0.30 & 0.0001 & -0.44 to -0.14 \\
\hline Sugar free gum was mentioned & Has not been mentioned & 0.19 & 0.24 & -0.13 to 0.51 \\
\hline 3 to 5 times/w & \multirow{3}{*}{ Participants eat cakes 6 or more times a week } & -0.06 & 0.55 & -0.27 to 0.14 \\
\hline $1-2$ times/w & & -0.06 & 0.58 & -0.27 to 0.16 \\
\hline Rarely & & -0.14 & 0.27 & -0.40 to 0.11 \\
\hline 3 to 5 times/week & \multirow{3}{*}{ Participants eat sweets 6 or more times/week } & -0.05 & 0.7 & -0.30 to 0.20 \\
\hline 1-2 times/week & & -0.40 & 0.002 & -0.61 to -0.14 \\
\hline Rarely & & -0.14 & 0.27 & -0.40 to 0.11 \\
\hline 3 to 5 times/week & \multirow{3}{*}{ Participants drinks fizzy drinks 6 or more times/week } & -0.02 & 0.9 & -0.28 to 0.24 \\
\hline 1-2 times/w eek & & -0.10 & 0.4 & -0.33 to 0.13 \\
\hline Rarely & & 0.04 & 0.71 & -0.15 to 0.22 \\
\hline Twice/day & \multirow{4}{*}{ Participants clean their teeth than twice/week } & -0.05 & 0.6 & -0.25 to 0.15 \\
\hline Once/day & & -0.12 & 0.32 & -0.37 to 0.12 \\
\hline Never & & 0.28 & 0.64 & -0.90 to 1.46 \\
\hline Occasionally & & 0.31 & 0.22 & -0.18 to 0.80 \\
\hline Dentist did not listen carefully & Dentist listened carefully & 0.65 & 0.0001 & 0.38 to 0.91 \\
\hline It was not enough time to discuss & It was enough time to discuss & 0.1 & 0.39 & -0.13 to 0.33 \\
\hline No decayed teeth & 1 or more number of decayed teeth & 0.33 & 0.0001 & 0.17 to 0.50 \\
\hline
\end{tabular}

1. Cohen S, Fiske J, Newton T. The impact of dental anxiety on daily living. Br Dent J 2000; 189: 385-390.

2. Heidari $E$, Banerjee A, Newton J T. Oral health status of non-phobic and dentally phobic individuals; a secondary analysis of the 2009 Adult Dental Health Survey. Br Dent J 2015; 219: 1-7.

3. Armfield J M, Stewart J F, Spencer A J. The vicious cycle of dental fear: exploring the interplay between oral health, service utilization and dental fear. BMC Oral Health 2007: 7: 1

4. Schuller A A, Willumsen T, Holst D. Are there differences in oral health and oral health behviour between individuals with high and low dental fear? Community Dent Oral Epidemiol 2003; 31: 116-121.

5. Thomson W M, Locker D, Poulton R. Incidence of denta anxiety in young adults in relation to dental treatment experience. Community Dent Oral Epidemiol 2000; 28 : 289-94.

6. Halsstrom T, Halling A. Prevalence of dentistry phobia and its relation to musing teeth, alveolar bone loss and dental care habits in an urban community sample. Acta Psychiatry Scand 1984; 70: 438-446.

7. De Jongh A, Schutjes M, Aartman IH. A test of Berggren's model of dental fear and anxiety. Eur J Oral SC 2011; 119: 361-365.

8. Watt R G, Listl S, Peres M \& Heilmann A (Eds.) Social inequalities in oral health: From evidence to action. London: UCL, 2015

9. Office for National Statistics. Social Survey Division and Information Centre for Health and Social Care, Adult Dental Health Survey, 2009. $2^{\text {nd }}$ Edition. Colchester, Essex: UK Data Archive [distributor], 2012.
10. O'Sullivan I, Lader D, Beavan-Seymour C, Chenery V, Fuller E, Sadler K. Foundation Report: Adult Dental Health Survey 2009 (Technical Report).The Information Centre for Health and Social Care, 2011.

11. Humphris G M, Crawford J R, Hill K, Gilbert A, Freeman R. UK population norms for the modified dental anxiety scale with percentile calculator: adult dental health survey 2009 results. BMC Oral Health 2013; 24: 13: 29.

12. Poulton $\mathrm{R}$, Waldie $\mathrm{K} E$, Thomson W M, Locker $\mathrm{D}$. Determinants of early vs late-onset dental fear in a longitudinal-epidemiological study. Behav Res Ther 2001; 39: $777-785$.

13. Agdal M L, Raadal M, Skaret E, Kvale G. Oral health and its influence on cognitive behavioural therapy in patients the Diagnostic and Statistical Manual Disorders-IV criteria for intra-oral injection phobia. Acta Odontologica Scandinavica 2010: 68: 98-105.

14. Schuller A A, Willumsen T, Holst D. Are there differences in oral health and oral health behviour between individuals with high and low dental fear? Community Dent Oral Epidemiol 2003; 31: 116-121.

15. Wisloff T F, Vassebd O, Asmyhr O. Dental anxiety, utilisation of dental services, and DMFS status on Norwegian military recruits. Community Dent Health 1995: 12:100103.

16. Mehrstedt M, Tönnies S, Eisentraut I. Dental fears, health status, and quality of life. Anesth Prog 2002; 51: 90-94.

17. Hagglin C, Berggren U, Hakeberg M, Ahlqvist M Dental anxiety among middle-aged and elderly women in Sweden. A study of oral state, utilisation of dental services and concomitant factors. Gerodontology 1996; 13: $25-34$.
18. Hakeberg M, Bergren U, Grondahl HG. A radiographic study of dental health in adult patients with dental anxiety. Community Dent Oral Epidemiol 1993; 21: 27-30.

19. McGrath C, Bedi R. Can dental attendance improve quality of life? Br Dent J 2001; 190: 262-265.

20. Abrahamsson K H, Bergeron U, Carlson S G. Psychosocial aspects of dental and general fears in dental phobic patients. Acta Odontological Scandinavica 2000; 58: 37-43.

21. White D A, Tsakos G, Pitss N B, Fuller E, Douglas G V A. Adult Dental Health Survey 2009: common oral health conditions and their impact on the population. Br Dent $J$ 2012; 213: 567-572.

22. Michaud P L, De Grandmont P, Feine I S, Emami E. Measuring patient based outcomes is treatment satisfaction associated with oral health related quality of life. J Dent 2012; 40: 624-631.

23. Moore R, Birn H, Kirkegaard E, Brodsgaard I, Scheutz F. Prevalence and characteristics of dental anxiety in Danish adults. Community Dent Oral Epidemiol 1993; 21: 292-296.

24. Milgrom P, Newton J T, Boyle C, Heaton L J, Donaldson $N$. The effects of dental anxiety and irregular attendance on referral for dental treatment under sedation within the National Health Service in London. Community Dent Oral Epidemiol 2010; 38: 453-459.

25. Humphris $G M$, King K. The prevalence of dental anxiety across previous distressing experiences. J Anxiety Disord 2011; 25: 232-236.

26. Thomson W M, Locker D, Poulton R. Incidence of dental anxiety in young adults in relation to dental treatment experience. Community Dent Oral Epidemiol 2000; 28 : 289-294. 